\title{
Can Credit Rating Agencies Play a Greater Role in Corporate Governance Disclosure?
}

\begin{abstract}
Purpose - The European Commission (EC) is currently examining methods to increase the effectiveness of corporate governance disclosures. This article examines whether the Credit Rating Agencies, both on account of their influence within the marketplace and also their methodological approach to rating "Governance", may have a greater role to play in the
\end{abstract} European Commission achieving those particular objectives.

Design/Methodology/Approach - This article is based upon a normative methodology, upon which the issue is contextualised and a proposal is put forward regarding a methodological alteration that can be instituted by the credit rating agencies.

Findings - The paper finds that the credit rating agencies may have a much greater role to play in meeting the objectives of the EC. Whilst the EC is focusing upon regulatory monitoring, the paper finds that there is a potential for a more efficient model within which the credit rating agencies adapt their methodologies to include 'corporate governance disclosure' into their rating processes.

Originality/Value - In presenting the idea that the "comply or explain" principles put forward by the EC are proving to be somewhat ineffective, the paper contributes to the field by suggesting there are private endeavours which may add a sense of impact to disclosure proceedings, rather than the purely public regime being envisioned. 


\section{Introduction}

When making their investment decisions, investors use a variety of measures to assess where they should invest their resources. With the current trend being to focus on what is colloquially termed "ESG" (Environmental, Social, and Governance) criteria, mainstream investors have made clear that the most important element for them is the Governance criteria, with a recent survey suggesting that nearly three-quarters of respondents find 'Governance [to be] the main factor incorporated' (CFA 2017, 5). It has been noted in the literature that a short-term approach was taken towards the concept of Governance in the lead-up to the Financial Crisis (McCluskey 2012, 26), and as such legislators and regulators have since aimed to address this issue. The European Commission, in focusing upon the information companies provide to the marketplace with regards to their compliancy with corporate governance regulations, have enforced that where companies deviate from governance codes, they must give details as to why (EC Directive 2006/46/EC). However, there have been a number of problems identified since this approach has been taken. Whilst companies have, by and large, failed to comply with the spirit of the regulatory endeavour, it has also been noted that there is an insufficient framework that surrounds the compliancerelated regulations, with the European Commission being unable to clearly identify who may take responsibility for monitoring, and the private marketplace being recognised as inadequate for providing a private solution; there exists in the marketplace specialist agencies who provide such monitoring services, but they have been found to lack the relevant expertise and resources to meet such a massive task (McCluskey 2012, 27).

In this article, the aim will be to assess a market participant who may be able to meet that demand: the Credit Rating Agencies (CRAs). Upon analysing what the aims of the 'Corporate Governance Statement' are and some of the problems that regulatory endeavour is facing, the article will go on to look at how the CRAs have been assessing 'Governance', and then whether their approach may be adapted to fulfil a vital need in the marketplace. There will be some discussion on another financial third-party - proxy advisors - because it is apparent that there exists plenty of capacity within the marketplace to undertake such roles. As we learn more about the issues raised, we will see that the issues identified correlate to a systemic occurrence, in that the impetus for such scrutiny tends to alleviate as the economic 
cycles oscillate, when what may be required is a counter-cyclic move. What is meant by this is that it may be the case that these third-parties need to increase their research into the governance of financial entities during periods when the demand for such aspects is reduced, mostly because in 'boom' periods investors are primarily concerned with returns, rather than how companies are governed - that alteration in perspective lies at the heart of the switch to long-termism (Griffith-Jones and Kimmis 2003, 93). Yet, in keeping with the request of the European Commission, that resolutions to these issues remain in the spirit of the compliancerelated regulations that were designed to enhance the informational flow within the marketplace, the article will conclude that the CRAs do have an important role to play, and a slight shift in their methodological approach may not only meet these needs, but contribute to a fundamental change in the ethos of the marketplace.

The remaining of this paper is organised as follows. The following section discusses the "Corporate Governance Statement" and the regulatory agenda being pursued in the EU currently, in relation to corporate governance. Section 3 examines the role of the credit rating agencies and examines how the concept of 'governance' is factored into their methodological processes. In section 4 the paper proposes a modified approach, whereby rating agencies may adapt their methodologies to assist with the regulatory agenda. Finally, the conclusion to the research conducted in the paper is established in Section 6.

\section{The Corporate Governance Statement: A Regulatory Agenda}

The European Commission, in detailing a 2006 Directive which has since been worked on and amended, stated that:

Companies whose securities are admitted to trading on a regulated market and which have their registered office in the Community should be obliged to disclose an annual corporate governance statement as a specific and clearly identifiable section of the annual report. The statement should at least provide shareholders with easily accessible key information about the corporate governance practices actually applied, including a description of the main features of any existing risk management systems 
and internal controls in relation to the financial reporting process (EC Directive 2006/46/EC).

An element of this Directive was to, essentially, enshrine the regulatory concept of 'comply or explain', whereby a company must disclose whether it has complied with a given code (or codes), and provide information for why they have not complied if they have chosen not to do so. The aim of 'comply or explain' is to provide a flexible regulatory framework, within which the companies ought to comply with the framework, but have the option of not doing so if the framework does not fit well with a specific element of their business. Additionally, the comply or explain principle offers an opportunity to increase the efficiency of the informational flow within the marketplace, with it being noted by an analytics organisation who provided the EC with the data for their Directive analysis that the aim is to "provide qualitative and comprehensive input that can subsequently be used by market players to make informed decisions' (RiskMetrics 2009, 179). The regulatory approach has been adopted within a number of jurisdictions, with the U.K. incorporating the approach after the Cadbury Report in 1992. Sir Adrian Cadbury once stated that a clear advantage of the approach is that 'through time the relevance of recommendations to board effectiveness and accountability become clear' (Cadbury 2002, 199). The sentiment behind Sir Cadbury's view is that the larger regulatory framework can identify themes on the back of compliancy rates, and then act to either remove them from the equation (if found to be not useful), or enshrine them within statutes (if found to be of importance), ultimately resulting in a more efficient regulatory system. However, since the EC has incorporated this approach into their framework, they have found that a number of dynamics are affecting the efficiency of the approach.

In a 'Green Paper' published in 2011, the European Commission noted the difficulties the approach has faced since being incorporated. In relation to the act of companies detailing why they have deviated from a given Corporate Governance Code, a study commissioned by the EC found that 'the overall quality of companies' corporate governance statements when departing from a corporate governance code recommendation is unsatisfactory', with it being found that in more than $60 \%$ of recorded cases, the companies did not provide sufficient information for their departures (EC 2011, 18). Whilst the cited report noted that the problem is not observed throughout the community - the UK, France, Sweden, and the Netherlands 
had the highest proportion of 'informative' explanations recorded (RiskMetrics 2009, 170) it did find that the lack of informative disclosure is having a demonstrable effect upon the marketplace's view of the approach, with only a quarter of investors being found to consider the quality of companies' disclosures as 'sufficiently good'. There is an argument to be had that countries such as the UK may well provide for more complete informational disclosures as the UK has been using the comply or explain approach for longer than the EU, but the EC has been trying to press ahead with potential solutions to the problems, rather than attempt to allow the principles of the regulatory approach to take greater effect over time.

One of the EC's potential responses lays in the concept of regulatory authorities from within member states taking a greater role in monitoring the disclosures of companies. In discussing this, the EC is clear in its thinking when it states that 'in most Member States, responsibility for enforcing the obligation to publish is left to investors who, depending on the culture and traditions in their Member States, often take little action... few Member States have public or specialised authorities check the completeness of the information provided (in particular, the explanations)'. The EC continues by declaring that comply or explain 'could work much better if monitoring bodies such as securities regulators, stock exchanges, or other authorities were authorised to check whether the available information (in particular, the explanations) is sufficiently informative and comprehensive' (EC 2011, 19). However, there have been issues with this approach identified in the literature, with it being asserted that the divergence across the globalised marketplace does not fit neatly in to this approach (Hermes et al 2006, 284), and that the approach does not actually have a clear effect upon the culture of firms (ibid 296). Whilst the EC does state that the approach should be aimed at companies registered within the community, the argument regarding the impact upon the migration of capital is still valid, as too is the declaration that comply or explain may not have a positive effect upon a company's culture, at least in the short- to mid-term. However, before we continue, there is merit to focusing on the fact that many companies do not provide sufficient information in their disclosures. That they do not raises a number of questions, and many of those questions point to issues that are systemic in nature.

MacNeil and Li suggest that two views can be taken with regards to the lack of informative disclosure cited in the EC's commissioned report. One of the reasons may be that near $60 \%$ 
of the companies analysed are in full compliance with their stated codes, but the scholars worry that, in fact, the issue may be that 'the market is not particularly concerned about noncompliance and there are no credible sanctions' (MacNeil and Li 2006, 488). There is a clear argument here that 'short-termism' is also a factor, in that the focus on short-term results, even to the point of only focusing on the next quarter's financial results (Rappaport and Bogle 2011,6), essentially trumps the consequences of non-compliance (and that suggests that a company acknowledges those consequences because, if MacNeil and Li are correct, then the absence of an acknowledged framework for sanctions will only contribute to shorttermism). Whilst MacNeil and Li stated this in 2006, the EC's current approach of suggesting that national regulatory bodies should take the lead in monitoring these disclosures suggests little has changed in the way of an efficient enforcement regime to accompany the comply or explain framework. Yet, whilst this points towards a failing on the behalf of regulators, it has also been suggested that the failing lies with the system moreover. For example, in opposition to the calls for national bodies to take the lead, the British regulator The Financial Reporting Council has been noted as stating that 'it is the task of the shareholders and the markets to monitor what directors say in their statements' (Keay 2015, 217). The lack of a defined approach to enforcing these regulatory endeavours, with two regulators in particular favouring opposing enforcement approaches (the EU favours regulatory action and the FRC favours investor action), suggests that the aim of encouraging long-termism is no closer to being met, even after such a defining event as the financial crisis.

In discussing the dynamic between investors, shareholders, and the companies who are being mandated to disclose their corporate governance practices, MacNeil and Li suggest that a better way to understand the reality of the situation would be to understand the framework as 'comply or perform', rather than 'comply or explain'. What the scholars mean by this is that investors are accustomed to understanding the efficiency of a company's corporate governance practice in relation to their financial performance, with investors being 'willing to accept a company's judgement as regards substance when times are good, but are less (or not) willing to accept it when financial performance is poor' (MacNeil and Li 2006, 492). It has been noted elsewhere in the literature that this concept of the investors focusing on their returns, above all else, is what is driving corporations to alter their approach to satisfy this short-termism-based demand (Redhead 2008, 248), with the EU itself lamenting the “passive” approach taken by many shareholders (Sikka and Stittle 2017, 2). Frentrop seeks to 
deconstruct the concept of a modern 'investor' in light of the pre-eminence of the 'institutional shareholder' led by managers, ultimately suggesting that the quest for managerial fees and compensation may be at the heart of the increase of short-termism (Frentrop 2012). Yet, whilst this 'cognitive bias' puts the responsibility at the feet of investors (which is not invalid), the actions of investors are extremely complicated. They are complicated because of the costs associated with performing this monitoring role; investors (whether retail or institutional) will be unlikely to engage in this research, as the costs associated somewhat negate the actual act of investing. To this end, it has been discussed widely in the literature that investors will 'routinely [adopt] a proxy to judge the merits of non-compliance' (ibid 490), which in turn reduces their costs. It has also been noted that proxies may be better placed to encourage the effective running of a company (on a shareholder's behalf) because of their experience in dealing with the intricacies of corporations (Köndgen 1993, 541). Whilst this article is focusing upon the role that CRAs may play in this position as a 'proxy', there is actually another industry which contains much bigger players in this field.

It is not the intention of this article to examine corporate governance advisory firms, otherwise known more colloquially as 'proxy advisors', because the focus of this article is on credit rating agencies and the subject has been covered in great detail within the literature already by noted scholars (Ringe 2016, 76-78; Ferri 2012, 195-197; de Luca 2017, 254-255; Bakewell and Darazsdi 2014, 185-196). However, to provide context, it is worth discussing the role they play within the disclosure-dynamic we are assessing here, together with some of the inherent problems that persist within this particular industry (many of which are shared with the Credit Rating Industry, for a number of reasons). The market for proxy advisors contain a number of key players, but the dominant players are Institutional Shareholder Services (ISS) and Glass Lewis. To compare the two industries, ISS records annual revenues in excess of $\$ 13$ billion, whilst Moody's records annual revenues of $\$ 4$ billion). The proxy advisors exist to provide recommendations based upon their assessments of the internal structures of companies, although it is has been stated (somewhat counterintuitively) that 'as a result of inevitable resource limitations' and companies' insistence of 'bunching' their disclosures, proxy advisors are often 'either unwilling or unable to afford qualitative consideration to companies' explanations for non-compliance with the Code, but instead opt to treat reasoned deviation from any Code provision as tantamount to simple breach' (Moore 
and Petrin 2017, 66). Yet, and again in a counterintuitive manner, it is still recognised as the case that 'for many matters they [proxy advisors] have become the de-factor arbiters of good governance' (OECD 2011, 61). Initially, this dynamic appears to be negative, in that investors are enlisting the services of agencies which do not invest in, nor have the technical ability (owing to the timing of company disclosures) to provide accurate corporate governance assessments, but the reality is much different. The reality alludes to a systemic dynamic that cannot be ignored, which is that dispersed investors will be mainly interested in return on investment above all else. It was mentioned earlier that short-sightedness was cited as a founding cause of the Financial Crisis, and understanding that investors use proxy advisors because they find it more cost-efficient to outsource their corporate governance analyses (Barker 2011, 157; Wen 2013, 232; Sheehan 2012, 121) seems to suggest that the short-sightedness is still prevalent in the marketplace. These factors allude to a core issue within the concept of displaced shareholders who, unless subscribed to some notion of directed investing (like, for example, ethical investment institutions), are focused on the rate of return on their investment. This again links to the concept of investors being willing to accept corporate governance practices if the company's financial performance is adequate. Furthermore, that investors are willing to forego this important aspect of their business by instead incorporating the views of an oligopolistic industry beset with conflicts of interest (Ringe 2016, 77) is, perhaps, further evidence of the investors' reluctance to take a greater role in improving the corporate governance within firms (as well as how they communicate their governance practices). To digress, the sentiment afforded by the FRC earlier, that investors are the vehicle within which change can be established, seems to be inherently flawed on this basis of fundamental short-sightedness within the mainstream investment market.

However, Moore and Petrin make the point that in this particular area, it is likely to be 'private dynamics' that initiate positive change, rather than public dynamics or administrative enforcement (Moore and Petrin 2017, 63). This is in opposition to the EC's push to incorporate national regulators into the framework more, but understanding the crucial importance of investor action suggests that Moore and Petrin may be correct in their understanding. Perhaps, as the scholars suggest, it is more pertinent to think of the framework as a public/private 'hybrid' of sorts - in that there may need to exist a system within which regulators seek to enforce certain parts of the governance disclosure regime, and private 
entities increase their efforts to enforce increased disclosure in other sectors, via investor activism or third-party pressure, for example - which brings us back to the objectives of this article. There are clearly issues within the EC's comply or explain framework, and that can likely be put down to the concept of there being a divergence between what the regulators envision is the reality, and what the reality of the situation actually is (Cash 2018a). This dynamic, unfortunately, is commonplace when it comes to regulators attempting to assert their authority over the actions (whether directly or indirectly) of dispersed investors. The reality of the situation is that dispersed investors are predominantly concerned with their returns (certainly in relation to so-called 'mainstream investors'), and as such cannot be corralled into taking decisions that will have long-term systemic benefits but that will incur short-term losses. Whilst we have discussed how one financial third-party is not performing adequately within this particular dynamic, that should not deter us from assessing another financial third-party that has expertise within this field of providing opinions on companies for the benefit of dispersed investors.

\section{The Role of the Credit Rating Agencies}

Credit rating agencies, in general, provide opinions on the creditworthiness of a given entity (corporate, sovereign, or financial instrument), but within their analyses are a number of particular elements which make up the cumulative rating they provide. With the growth of the 'ESG' concept within the sector, the leading rating agencies have been at pains to declare that they do indeed incorporate ESG considerations into their analyses, particularly now that they have aligned with the Principles for Responsible Investment (PRI) movement initiated by the United Nations in the wake of the Financial Crisis (both S\&P and Moody's are signatories). In addressing concerns that the agencies do not incorporate ESG into their rating methodologies enough, Standard \& Poor's (the leading CRA) stated that 'ESG factors are analysed at various points in ratings methodology', although environmental and social aspects are not routinely incorporated into assessing the business risk profile (PRI 2017, 20). In relation to corporate governance, which is what we are concerned with here, S\&P noted that 'management decision making and the effectiveness of board oversight are further reviewed and assessed with the management and governance modifier in our ratings methodology' (ibid), which has a number of connotations. The first is that it is clear that the 
CRAs do indeed incorporate ESG into their methodologies, but it is interesting to note what $\mathrm{S} \& \mathrm{P}$ has decided is pertinent governance information; the disclosure of these practices does not seem to be factored in. However, before we look at this important issue further, there is an error in the literature that needs to be highlighted.

Many resources in the literature state that CRAs consider corporate governance in their methodologies. Some have gone further by stating that 'since the 1990s, credit rating agencies have offered corporate governance assessments with the aim of evaluating governance risk' (Louizi and Kammoun 2016, 363). This author has argued elsewhere that it is of crucial importance that every minute detail is scrutinised when it comes to understanding the CRAs, and this represents another occasion where an error assists with the overly-positive understanding of the CRAs role and usefulness. Writing in 2016, the authors praise S\&P for providing 'Corporate Governance System ratings (CGS), stating that S\&P 'was one of the first agencies to evaluate the quality of companies' corporate governance systems by developing a specific rating (ibid 365) that focused upon elements like director compensation, the usage of company resources, bonus systems, and accounting controls. However, this reaction to the Enron-era was not continued, with S\&P discontinuing production of these ratings in 2004/5 (Taub 2005). In actual fact, S\&P did not begin to utilise their 'management and governance modifier' until 2012/13, which suggests to us that the arguments detailed earlier, that investors are willing to rely on financial performance alone when the economy is in its 'boom' period, is rather accurate.

Returning to the issue of governance and how the agencies view it when developing their ratings, two aspects are abundantly clear. Investors are absolutely certain that Governance is the most important element of ESG, with the PRI sourcing statements from their 1800 investor signatories: one stated that Governance 'is always the most important factor and always will be', while another stated that 'the biggest weight in our process is governance' these are very much representative of the qualitative responses (PRI 2017). The rating agencies concur, with a number of agencies confirming that 'governance is the core analytical driver' (Scope Ratings), 'Governance is more important because it is more volatile and thus moves markets' (S\&P), and that 'governance is very important to us, interviews start with governance issues because they are fundamentally important for the continuity of the firm' 
(Liberum Ratings). Initial forays into this qualitative collection are extremely positive, with all sides and the PRI affirming that both parties are allocating more resources than ever before to focus upon ESG-related issues (PRI 2017, 11), which for the CRAs includes hiring dedicated ESG analysts and making a concerted effort to communicate how ESG is being incorporated into their methodological processes. However, whilst the PRI's analysis is extremely useful and initially very positive, it does not last. Whilst it has been noted in the narrow literature on this issue that there is a notable variance between ratings methodologies within the different agencies anyway (Louizi and Kammoun 2016, 375), it is the agencies' views on the importance of Governance in reality that makes for interesting reading.

Methodologically, the CRAs have an issue with the usefulness of ESG incorporation (even the Governance element which has been described by CRAs as being particularly important) because of what they label as 'forward visibility'. Their arguments are that, for corporate bonds certainly, it is extremely difficult to incorporate aspects of Governance into the ratings analysis when the terms of the corporate bonds are not particularly extended. The sentiment behind this line of reasoning is that corporate bond rating users want to know of the creditworthiness of the issuing entity over a given (and often limited) timeframe, and incorporating analysis that may dictate there are underlying governance issues which may take years to come to fruition are not relevant for those users. That perhaps makes sense, to some extent, as the agencies' 'vision' will often differ depending upon the type of bond that they are rating. However, this has not stopped investors from criticising the CRAs, with some being noted as stating 'there is scope to better capture indirect, embedded ESG risks which are values/supply chain related', to which Moody's responded by stating that 'ESG considerations are rarely the main driver of credit outcomes. Broader ratings factors - notably the financial strength of a given debt issuer - will typically form a more important part of our credit assessment' (PRI 2017, 28; Moody’s 2015). S\&P concurred with their oligopolistic partner, stating that 'credit ratings for corporates have a shorter time horizon than the time horizon over which most ESG risks tend to materialise and this is causing perception issues' (PRI 2017 26). These determinations raise the question of whether the CRAs can ever fulfil their pledge to fully incorporate the principles dictated by the PRI. 
However, rather than their actual incorporation of ESG considerations into their methodological analyses, the PRI has determined that one of the biggest issues affecting the CRA/PRI relationship is one of disclosure; the PRI state that 'the main challenge for CRAs is on the disclosure and transparency front, not so much on putting in place an ESG integration framework, which they have already' (ibid 17). The PRI investor signatories go further by declaring that they believe that 'CRAs should take a more proactive approach to highlighting ESG considerations into their analysis' (ibid 27). The signatories appear to be calling for more communication of how ESG integrates into the rating process whether or not it affects the creditworthiness of the issuing entity, which alludes to a call to fundamentally change the fabric of the modern marketplace. Yet, whilst it is not an invalid request, the agencies are clear that there are underlying difficulties in meeting that need, with S\&P in its most recent update to their management and governance criteria declaring that the subfactor is the most subjective and qualitative aspect to their business (S\&P 2012, 52).

Whilst the divergence between the two parties is clear, the dynamics underpinning that relationship are less so. One of the most important underlying dynamics is that despite regulatory endeavours to reduce 'credit rating addiction' (Cash 2018b), it is still the case that 'a majority [of investors are] also constrained by ratings, either because investors benchmarked their investments against indices (which in turn may be partially constrained by credit ratings) or because their investment strategy or that of their clients has credit rating limits' (PRI 2017, 33). So on one side the flow of capital is being fed through the credit rating industry, but on the other the CRAs have an enormous amount of power at their disposal. The literature is clear on this, with it being asserted that 'credit rating agencies may even be in a position to exercise an explicit veto over certain options (in the corporate governance of firms or the economic policies of a state) by using a ratings downgrade', and that 'there is indeed a high degree of compliance with credit rating agencies' standards... [public and private market actors] tend to adjust their behaviour to meet the criteria of creditworthiness set by credit rating agencies' (Kruck 2011, 65). Whilst this could lead to an interesting debate about whether the profit-driven focus of market participants (and perhaps even the shortsightedness discussed earlier) is being developed by the rating agencies, or whether they are merely reacting to that culture, our focus must remain on the potential role that the agencies may play in improving the quality of corporate governance statements. 


\section{Utilising an Existing Framework}

Leaving aside the deficiencies within the proxy advisor industry for one moment, there is plenty that could be done within the ratings industry to positively affect the issues identified by the European Commission. With investors putting pressure on the agencies to adapt their methodological approach and, in truth with the CRAs seemingly taking some notice, there exists an opportunity now to enact meaningful change in the sector. With the move by the leading agencies to incorporate ESG further into their analyses with the hiring of specialist ESG analysts (and through targeted M\&A strategies - S\&P's recent purchasing of 'Trucost' alludes to this further), it is not unimaginable that the leading agencies could add the concept of corporate governance disclosure to their methodological approaches. If they were to do so, the aspects of the underlying dynamic that exists between investors, issuing companies, and the CRAs could have a positive effect upon the quality of the corporate governance statements. Imagine for one moment that corporate governance disclosures were factored into ratings in a systematic manner; what may happen is that issuing companies could have their ratings negatively affected if they deviate from a corporate governance code but then subsequently provide insufficient information for why they chose to do so - alternatively, a company could have their credit rating enhanced if they deviated but provided sufficient information for their decision. This altered approach would fall neatly into the European Commission's insistence that solutions to the problems identified fall within the 'spirit' of the comply or explain Directive, and would also potentially develop a pathway for the financial system to move away from the short-termism that has been identified as plaguing the marketplace. Whether the agencies would make this methodological alteration and communicate this thoroughly to the marketplace is, in truth, unknown, but the potential for this to take place does exist, and more importantly would represent a practical solution to the issue of unsatisfactory corporate governance disclosures.

It was discussed earlier how the EC is placing emphasis upon the need for regulatory bodies to take a greater role in monitoring disclosure rates from companies caught by the EC Directives regarding corporate governance statements. It was also mentioned that the FRC in the UK see the investors as being the vehicle for change and control within this sector, again in relation to the disclosures from companies. However, both of these aims contain obvious 
flaws, with the EC's approach resulting in increased expenditure for regulatory bodies, and the FRC's approach resulting in a request for increased activism from investors who, as we have seen, are apparently configured to do the opposite (as long as they see the returns they require, of course). Therefore, there is a potential for the need for a 'middle-ground' approach which may enable the same results to be obtained, and in the credit rating agencies there exists the potential to achieve that aim. The sanctioning power attached to the ratings of the agencies present the opportunity to encourage increased disclosure rates - on the basis of potentially achieving a higher rating as a result - and also provide a real sanction that is apparently missing from the marketplace. If the rating agencies were to add this dynamic to their methodologies, particularly in conjunction with the 'governance' element of their rating methodologies that exist already, then that small methodological alteration could have a massive impact upon the aims of the regulatory system being developed by the EC. It is a widely-held view that the rating agencies possess a massive 'power' or 'influence' within the marketplace (Serrano 2013, 47; Partnoy 2002, 66), and it is suggested here that this 'power' be utilised to assist in achieving the objectives of increased disclosure rates in relation to the 'corporate governance statement'. Not only may this approach achieve the objectives set, but it would also allow for regulatory bodies to allocate their resources to other initiatives, whilst also utilising a market mechanism that many (institutional) investors already utilise; the development of this 'hybrid' approach has the potential to create many benefits for a number of parties. Furthermore, the methodological alteration required would be more than achievable for the agencies, and would enhance their position within the dynamic that exists between them and the investors who utilise their services.

\section{Conclusion}

The European Commission's objectives of improving the quality of corporate governance statement disclosures is indeed a very important one, because the community needs the 'comply or explain' principle to be fundamentally incorporated into the financial fabric within the community. However, whilst the EC has been hinting at incorporating a public solution to the problem, there is merit to the suggestion that a private, or at least a 'hybrid' solution would be more practicable. In presenting the idea that the CRAs could adapt their methodologies to incorporate the quality of CG statement disclosure into their 
methodological processes, this article has endeavoured to offer that 'hybrid' solution. However, the task of implementing the comply or explain regulatory framework should be viewed from as wide a perspective as possible, with the emphasis being on the concept of a framework; there is no reason why the CRAs and proxy advisors could not both incorporate this aim into their methodologies, because it is clear there is an appetite amongst investors. Whilst these financial third parties may claim that extra resources would be needed to conduct and incorporate such analyses, the long-term understanding may be that the third parties would become even more integral to the financial system, which would further ensure their continued successes. Yet, the most important aspect is that the EC's objective of establishing the 'comply or explain' principle would be given the 'teeth' it is lacking currently, which has been noted to be one of the largest impediments to its successful implementation.

\section{Bibliography}

Adrian Cadbury, Corporate Governance and Chairmanship: A Personal View (Oxford University Press 2002).

Alfred Rappaport and John C Bogle, Saving Capitalism from Short-Termism: How to Build Long-term Value and Take Back our Financial Future (McGraw-Hill Professional 2011).

Amanda McCluskey 'ESG analysis as a predictor of quality of management in investment decision-making' in Iveta Cherneva The Business Case for Sustainable Finance (Routledge 2012).

Amir Louizi and Radhouane Kammoun, 'Evaluation of corporate governance systems by credit rating agencies' [2016] 20 Journal of Management \& Governance 2.

Andreas Kruck, Private Ratings, Public Regulations: Credit Rating Agencies and Global Financial Governance (Springer 2011).

Andrew Keay, Board Accountability in Corporate Governance (Routledge 2015).

Antonio S Serrano, Financial Crisis (Lulu 2013).

CFA Institute, Environmental, Social and Governance (ESG) Survey (CFA Institute 2017).

Daniel Cash 'Sustainable finance ratings as the latest symptom of "rating addiction" [2018b]

3 Journal of Sustainable Finance \& Investment.

Daniel Cash Regulation and the Credit Rating Agencies: Restraining Ancillary Services (Routledge 2018a).

European Commission Directive 2006/46/EC 
Fabrizio Ferri, "'Low-cost” Shareholder Activism: A Review of the Evidence' in Claire A Hill, James L Krusemark, Brett H McDonnell, and Solly Robbins, Research Handbook on the Economics of Corporate Law (Edward Elgar 2012).

Frank Partnoy, 'The Paradox of Credit Ratings' in Richard M Levich, Giovanni Majnoni, and Carmen Reinhart, Ratings, Rating Agencies and the Global Financial System (Kluwer 2002).

Iain MacNeil and Xiao Li, “"Comply or Explain”: Market discipline and non-compliance with the Combined Code' [2006] 14 Corporate Governance: An International Review 5.

Johannes Köndgen, 'Duties of Banks in Voting Their Clients' Stock' in Theodor Baums, Richard M Buxbaum, and Klaus J Hopt, Institutional Investors and Corporate Governance (Walter de Gruyter 1993).

Keith Redhead, Personal Finance and Investments: A Behavioural Finance Perspective (Routledge 2008).

Kym M Sheehan, The Regulation of Executive Compensation: Greed, Accountability and Say on Pay (Edward Elgar 2012).

Marc Moore and Martin Petrin, Corporate Governance: Law, Regulation and Theory (Macmillan 2017).

Moody's, Moody's: Incorporating Environmental, Social and Governance Risks into Credit Analysis (2015) https://www.moodys.com/research/Moodys-Incorporating-environmentalsocial-and-governance-risks-into-credit-analysis--PR_334072.

Nicola de Luca, European Company Law: Text, Cases and Materials (CUP 2017).

Niels Hermes, Theo J.B.M. Postma, and Orestis Zivkov, 'Corporate Governance Codes in the European Union: Are They Driven by External or Domestic Forces?' [2006] 2 International Journal of Managerial Finance 4.

OECD, Corporate Governance: The Role of Institutional Investors in Promoting Good Corporate Governance (OECD Publishing 2011).

Paul Frentrop, 'Short-termism of Institutional Investors and the Double Agency Problem' [2012] SSRN https://papers.ssrn.com/sol3/papers.cfm?abstract_id=2249872.

Prem Sikka and John Stittle, 'Debunking the Myth of Shareholder Ownership of Companies: Some Implications for Corporate Governance and Financial Reporting' [2017] Critical Perspectives on Accounting.

Principles for Responsible Investment, ESG, Credit Risk and Ratings - The State of Play https://www.unpri.org/download_report/36678.

RiskMetrics Group, Study on Monitoring and Enforcement Practices in Corporate Governance in the Member States (2009)

http://ec.europa.eu/internal_market/company/docs/ecgforum/studies/comply-or-explain090923_en.pdf.

Roger Barker, 'Ownership structure and shareholder engagement: reflections on the role of institutional shareholders in the financial crisis' in William Sun, Jim Stewart, and David Pollard, Corporate Governance and the Global Financial Crisis: International Perspectives (CUP 2011). 
Shuangge Wen, Shareholder Primacy and Corporate Governance: Legal Aspects, Practices and Future Directions (Routledge 2013).

Standard \& Poor's, General Criteria: Methodology: Management and Governance Credit Factors for Corporate Entities and Insurers (2012).

Stephany Griffith-Jones and Jenny Kimmis, 'Stabilising capital flows to developing countries' in John Grieve-Smith and Jonathan Michie, Global Instability: The Political Economy of World Economic Governance (Routledge 2003).

Stephen Taub, 'S\&P Stops Issuing Governance Scores' [2005] CFO (Sept 9)

http://ww2.cfo.com/risk-compliance/2005/09/sp-stops-issuing-governance-scores/.

The European Commission, Green Paper: The EU Corporate Governance Framework (COM 164 2011).

Thomas Bakewell and James J Darazsdi, Claiming Your Place at the Boardroom Table: The Essential Handbook for Excellence in Governance and Effective Directorship (McGraw-Hill Professional 2014).

Wolf-Georg Ringe, The Deconstruction of Equity: Activist Shareholders, Decoupled Risk, and Corporate Governance (OUP 2016). 